\title{
Type, source, adequacy and outcome of consultations requested from the department of general surgery: retrospective cohort study
}

\author{
Metin Leblebici®, Orhan Alimoğlu®
}

Department of General Surgery, Istanbul Medeniyet University Faculty of Medicine, Istanbul, Turkey

\section{ABSTRACT}

Objectives: To evaluate consultations requested from the department of general surgery in terms of type, source and adequacy and outcome regarding general surgery practice.

Methods: A total of 4706 consultations requested from the department of general surgery during the 2019 calendar year were included in this retrospective study. Data on patient demographics, type of consultation (urgent, routine), the requesting clinic, time of request, response time to consultation request (min), diagnosis and management of consulted patients by general surgery clinic and survivorship status were recorded.

Results: Consultations were urgent (69.0\%) and made outside office hours (66.0\%) in most of cases and more commonly requested by the emergency department $(67.5 \%)$. The surgical pathology was confirmed only in $1338(28.4 \%)$ consultations, while more commonly for urgent vs. routine requests $(37.4 \mathrm{vs} .8 .5 \%, p=0.001)$, for consultations requested by emergency department (ranged 30.9 to $40.0 \%$ ) vs. other clinics (ranged $0.0 \%$ to $19.1 \%, p=0.001)$ and for diseases of colon-rectum-anus $(100.0 \%, p=0.001)$ than other disorders. The likelihood of urgent consultations $(72.0 \%$ vs. $37.3 \%, p=0.001)$ and post-consultation inpatient management $(90.5 \%$ vs. $24.7 \%, p=0.001)$ and were more likely among survivors vs. non-survivors.

Conclusions: In conclusion, our findings revealed that most of the consultations were urgent, outside the office hours and outpatient consultations requested by the emergency department, while surgical pathology was confirmed only in one third of consultations. Our findings indicate improved consultation practice particularly for routine requests by non-emergency clinics to prevent the incompatible or unnecessary consultation requests and related healthcare resource utilization.

Keywords: Consultation request, general surgery, urgent, routine, adequacy of request

A pecialty consultation is a critical aspect of healthcare practice in terms of provision of the highquality medical and surgical services via follow-up and treatment of a patient in accordance with clinical knowledge, experience and recommendations of consultant doctor related to the specific condition that requires care beyond the scope of the clinic in charge of the patient [1-4].
Specialty consultation also considered a laborious task necessitating appropriate specialist triage to ensure timely evaluation of consulted patients as well as appropriate co-management between primary care and specialty care, given the likelihood of potential hazards (i.e. life-threatening outcomes, legal issues) in case of consultation delays 1, 4-6].

General surgery is the most comprehensive surgi- 
cal discipline that deals a wide range of diseases [3], while surgical yield is considered a unique measure of efficiency among surgical services that shows the percentage of ambulatory surgical consultations resulting in a scheduling of an operative intervention $[6,7]$.

This single center retrospective study was therefore designed to evaluate consultations requested from the department of general surgery during the 2019 calendar year at a tertiary care hospital in terms of type and source of consultations as well as their adequacy and outcome regarding general surgery practice.

\section{METHODS}

\section{Study Population}

In this retrospective study, a total of 4706 electronic consultations (mean age: $53.7 \pm 21.3$ ) years, $54 \%$ were females) requested from the department of general surgery at hospital between January 1st 2019 and December 31st 2019 were included.

The study was conducted in full accordance with local Good Clinical Practice (GCP) guideline and current legislations, while the permission was obtained from the institutional ethics committee for the use of patient data for publication purposes (Date of Approval: 5/02/2020; Reference number/Protocol No:2020/0088). The work has been reported in line with the STROCSS criteria [8] and was registered by Research Registry with the Unique Identifying Number 5998 .

\section{Hospital Characteristics}

The study hospital is a 660-bed tertiary university hospital located in a city within the metropolitan area and serving for all medical specialties including a single general surgery clinic for entire surgery sub-specialties as well as anesthesia and internal medicine intensive care units.

\section{Assessments}

Data on patient demographics (age, gender), type of consultation (urgent, routine), the requesting clinic, time of request, response time to consultation request (min), type of admission, diagnosis and management of consulted patients by general surgery clinic and survivorship status were retrieved from hospital records. Patient demographics and consultation parameters were evaluated with respect to confirmation of operative or non-operative surgical pathology (yes vs. no) after consultation, general surgery ward hospitalization (yes vs. no) and type of consultation made by the consulting service based on indication (urgent vs. routine).

\section{Statistical Analysis}

Statistical analysis was made using NCSS (Number Cruncher Statistical System) 2007 (Kaysville, Utah, USA). Pearson Chi-square test, Fisher's exact test and Fisher-Freeman-Halton tests were used for the comparison of categorical data, while numeric data were analyzed using Student-t test and Mann-Whitney $\mathrm{U}$ test depending on the normality findings. Data were expressed as mean \pm standard deviation (SD), median (minimum-maximum) and percent (\%) where appropriate. $P<0.05$ was considered statistically significant.

\section{RESULTS}

\section{Overall Characteristics}

Overall, mean patient age was 53.7 (range, 17 to 102) years, and $2541(54.0 \%)$ of 4706 consultations were requested for female patients. The median response time to the consultation was 89 (range, 20 to $1440) \mathrm{min}$. Consultations were urgent $(69.0 \%)$ and made outside office hours $(66.0 \%)$ in most cases and more commonly requested by the emergency department $(67.5 \%, 45.9 \%$ from green zone) and mostly for outpatients (68.5\%) and upper GI disorders (58.7\%) (Table 1). The surgical pathology was confirmed only in $1338(28.4 \%)$ consultations, while for 3368 (71.6\%) consultations there was no surgical pathology or need for treatment by general surgery physicians. Of 1338 consultations with confirmed surgical pathology, 1086 $(81.2 \%)$ were managed on an inpatient basis in the general surgery ward, while the treatment decisions involved medical treatment in $49.2 \%$ of cases, surgical treatment in $36.8 \%$ of cases, and transfer to another clinic in $14 \%$ of patients. Overall, mortality occurred in $394(8.4 \%)$ of 4706 consultations patients and 190 $(48.2 \%, 14.2 \%$ of those with surgical pathology) were patients with confirmed surgical pathology (Table 1).

Study Variables According to Confirmation of Surgical 
Table 1. Study variables according to confirmation of surgical pathology after consultation

\begin{tabular}{|c|c|c|c|c|c|}
\hline & & Total & Confirmatior & f a surgical p & thology \\
\hline & & & No & Yes & $p$ value \\
\hline Age (year) & Mean \pm SD & $53.7 \pm 21.3$ & $54.0 \pm 21.3$ & $53.1 \pm 21.3$ & $0.197^{\mathrm{a}}$ \\
\hline & Median (min-max) & $54(17-102)$ & $54(17-102)$ & $53.5(18-96)$ & \\
\hline Gender, n (\%) & Female & $2541(54.0)$ & $1942(76.4)$ & $599(23.6)$ & $0.001^{b}$ \\
\hline & Male & $2165(46.0)$ & $1426(65.9)$ & $739(34.1)$ & \\
\hline Type of & Urgent & $3250(69.0)$ & $2036(62.6)$ & $1214(37.4)$ & $\mathrm{0.001}^{\mathrm{b}}$ \\
\hline & Routine & $1456(30.9)$ & $1332(91.5)$ & $124(8.5)$ & \\
\hline $\begin{array}{l}\text { Requested by, } \\
\text { n (\%) }\end{array}$ & $\begin{array}{l}\text { Emergency department } \\
\text { (green zone) }\end{array}$ & $2158(45.9)$ & $1294(60.0)$ & $864(40.0)$ & $0.001^{\mathrm{b}}$ \\
\hline & $\begin{array}{l}\text { Emergency department } \\
\text { (yellow zone) }\end{array}$ & $962(20.4)$ & $637(66.2)$ & $325(33.8)$ & \\
\hline & $\begin{array}{l}\text { Emergency department (red } \\
\text { zone) }\end{array}$ & $55(1.2)$ & $38(69.1)$ & $17(30.9)$ & \\
\hline & Internal medicine & $737(15.7)$ & $642(87.1)$ & $95(12.9)$ & \\
\hline & Anesthesia & $94(2.0)$ & $76(80.9)$ & $18(19.1)$ & \\
\hline & Obstetrics and Gynecology & $319(6.8)$ & $310(97.2)$ & $9(2.8)$ & \\
\hline & Infectious diseases & $68(1.4)$ & $65(95.6)$ & $3(4.4)$ & \\
\hline & Neurosurgery & $38(0.8)$ & $38(100.0)$ & $0(0.0)$ & \\
\hline & Neurology & $41(0.9)$ & $41(100.0)$ & $0(0.0)$ & \\
\hline & Orthopedics & $70(1.5)$ & $65(92.9)$ & $5(7.1)$ & \\
\hline & Urology & $85(1.8)$ & $84(98.8)$ & $1(1.2)$ & \\
\hline & Other & $79(1.7)$ & 78 (98.7) & $1(1.3)$ & \\
\hline Time of request, & Within office hours & $1600(34.0)$ & $1233(77.1)$ & $367(22.9)$ & $0.001^{\mathrm{b}}$ \\
\hline & Outside office hours & $3106(66.0)$ & $2135(68.7)$ & $971(31.3)$ & \\
\hline Type of admission, $n$ & Outpatient & $3223(68.5)$ & $2017(62.6)$ & $1206(37.4)$ & $\mathrm{O.001}^{\mathrm{b}}$ \\
\hline & Inpatient & $1483(31.5)$ & $1351(991.1)$ & $132(8.9)$ & \\
\hline Diagnosis, n (\%) & Upper GI disorder & $2761(58.7)$ & $1810(65.6)$ & $951(34.4)$ & $0.001^{b}$ \\
\hline & Hepatobiliary disorder & $281(6.0)$ & $151(53.7)$ & $130(46.3)$ & \\
\hline & $\begin{array}{l}\text { Colon, rectum, anus } \\
\text { disorder }\end{array}$ & $107(2.3)$ & $0(0.0)$ & $107(100.0)$ & \\
\hline & Trauma & $210(4.5)$ & $160(76.2)$ & $50(23.8)$ & \\
\hline & Skin-soft tissue disorder & $131(2.8)$ & $121(92.4)$ & $10(7.6)$ & \\
\hline & Other & $1216(25.8)$ & $1126(92.6)$ & $90(7.4)$ & \\
\hline Hospitalization after & No & $3620(76.9)$ & $3368(93.0)$ & $252(7.0)$ & $0.001^{b}$ \\
\hline & Yes & $1086(23.1)$ & $0(0.0)$ & $1086(100.0)$ & \\
\hline Treatment plan, $n$ & Medical treatment & $658(14.0)$ & $0(0.0)$ & $658(100.0)$ & $0.001^{b}$ \\
\hline & Surgery & $492(10.5)$ & $0(0.0)$ & $492(100.0)$ & \\
\hline & Transfer to another ward & $392(8.3)$ & $204(52.0)$ & $188(48.0)$ & \\
\hline & $\begin{array}{l}\text { No need for treatment by } \\
\text { GS }\end{array}$ & $3164(67.2)$ & $3164(100.0)$ & $0(0.0)$ & \\
\hline Mortality, n (\%) & No & $4312(91.6)$ & $3164(73.4)$ & $1148(26.6)$ & $0.001^{b}$ \\
\hline & Yes & $394(8.4)$ & $204(51.8)$ & $190(48.2)$ & \\
\hline Response time to & Mean \pm SD & $116.7 \pm 103.2$ & $117.7 \pm 102.2$ & $114.2(105.7)$ & $0.115^{\mathrm{c}}$ \\
\hline & Median (min-max) & $89(20-1440)$ & $89(20-1440)$ & $88(20-1440)$ & \\
\hline
\end{tabular}

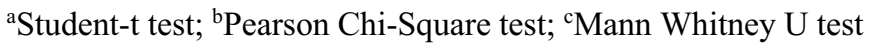




\section{Pathology}

Amongst the consultations requested from the department of general surgery, confirmation of a surgical pathology was significantly more likely for male vs. female patients ( 34.1 vs. $23.6 \%, p=0.001$ ), for urgent vs. routine requests ( 37.4 vs. $8.5 \%, p=0.001)$, for consultations requested by emergency department (ranged from $30.9 \%$ in red zone to $40.0 \%$ in green zone) vs. other clinics (ranged $0.0 \%$ to $19.1 \%, p=$ 0.001 ) as well as those requested by internal medicine $(12.9 \%)$ and anesthesia (19.1\%) vs. clinics other than emergency department (ranged $0.0 \%$ to $7.1 \%, p=$ 0.001 ) (see Table 1). Confirmation of surgical pathology was also more likely for consultation requests made outside vs. within office hours (31.3 vs. $22.9 \%$, $p=0.001)$ and for consultations requested for outpatients vs. inpatients ( 37.4 vs. $8.9 \%, p=0.001)$ (Table $1)$. The likelihood of confirmed surgical pathology was higher for gastrointestinal disorders (ranged $34.4 \%$ to 100.0$)$ vs. trauma $(23.9 \%)$, soft tissue $(7.6 \%)$ and other $(7.4 \%)$ disorders, and for trauma vs. soft tissue and other disorders $(p=0.001)$. Specifically, diseases of colon-rectum-anus $(100.0 \%)$ were associated with the highest likelihood of confirmed surgical pathology, as followed by hepatobiliary disorder (46.3\%), upper GI disorder (34.4\%) and trauma $(23.8 \%)(p=0.001)$ (see Table 1). Consultations resulted in confirmed surgical pathology were more likely to managed on an inpatient basis than on an outpatient basis (100 vs. $7.0 \%, p=0.001)$ and also with medical or surgical treatment $(100.0 \%$ for each) rather than transfer to another ward $(48.0 \%)(p=0.001)$ (see Table 1). The likelihood of a confirmed surgical pathology was higher among non-survivors vs. survivors ( 48.2 vs. $26.6 \%, p=0.001$ ), while no significant difference was noted in the likelihood of confirmed surgical pathology after consultations in terms of patient age and response time to consultation (see Table 1).

\section{Study Variables According to General Surgery Ward Hospitalization}

Inpatient management via hospitalization at general surgery ward was more likely for consultations requested for younger vs. older patients (mean age: 51.7 \pm 20.8 ) vs. $58.9 \pm 22.6$ years, $p=0.001)$, for outpatients vs. inpatients ( 85.1 vs. $45.5 \%, p=0.001)$ and for urgent vs. routine requests ( 84.6 vs. $47.6 \%, p=$
0.001). Consultations requested by emergency (green zone, 99.4\%) and obstetrics-gynecology (88.9\%) departments were associated with highest rate of hospitalization at a general surgery ward, as followed by those requested by yellow zone (76.6\%) and red zone (76.5\%) emergency, internal medicine $(46.3 \%)$ and anesthesia $(22.2 \%)$ departments $(p=0.001)$ (Table 2$)$. The skin-soft tissue disorders (100.0\%) were associated with the highest (100.0\%) likelihood of hospitalization, as followed by upper GI disorder $(87.2 \%)$, hepatobiliary disorder $(86.2 \%)$ and trauma $(84.0 \%)$, while likelihood of hospitalization was lowest for diseases of colon-rectum-anus $(6.5 \%)(p=0.001)$. Hospitalization was required for all of upper GI, hepatobiliary and hernia surgeries, whereas only for $40.0 \%$ of proctology surgeries $(p=0.001)$ (see Table $2)$. General surgery ward hospitalization was also more likely in survivors vs. non-survivors vs $(90.5 \%$ vs. $24.7 \%, p=0.001$, while no significant difference was noted in the likelihood of hospitalization in terms of patient gender, time of request and response time to consultation (see Table 2).

\section{Study Variables According to Type of Consultation}

Urgent vs. routine general surgery consultations were associated with younger patient age $(51.6 \pm 21.5$ vs. $58.4 \pm 20.3$ years, $p=0.001$ ), predominance of requests by emergency department (ranged 99.8 to $100.0 \%$ ) than by other clinics (ranged 0.0 t $16.3 \%, p$ $=0.001$ ), higher rates of outside than within office hours requests ( 79.8 vs. $48.1 \%, p=0.001)$, outpatient than in-patient admissions (99.7 vs. $2.5 \%, p=0.001)$ and presence than absence of inpatient management by general surgery clinic ( 94.6 vs. $61.4 \%, p=0.001$ ) (Table 3). The likelihood of urgent consultations was significantly higher for colon, rectum, anus disorders (98.1\%) and upper GI disorder (87.3\%) than for hepatobiliary disorder $(60.9 \%)$, skin-soft tissue disorder $(65.6 \%)$ and trauma $(69.0 \%)(p=0.001)$. Urgent vs. routine general surgery consultations were associated with higher rate of medical $(95.9 \%)$ or surgical treatment $(93.5 \%)$ than transfer to another ward (37.8\%) (see Table 3$)$. Urgent vs. routine consultations $(72.0 \%$ vs. $37.3 \%, p=0.001)$ were more likely among survivors vs. non-survivors, and associated with lower response time to consultation request (median 77 vs. 122 min, $p=0.001$ ), while no significant difference was noted in the likelihood of hospitalization in terms of 
Table 2. Study variables according to hospitalization after consultation

\begin{tabular}{|c|c|c|c|c|}
\hline & & \multicolumn{3}{|c|}{ Hospitalization at general surgery ward } \\
\hline & & No $(n=252)$ & Yes $(n=1086)$ & $p$ value \\
\hline \multirow[t]{2}{*}{$\overline{\text { Age (year) }}$} & Mean \pm SD & $58.9 \pm 22.6$ & $51.7 \pm 20.8$ & $0.001^{\mathrm{a}}$ \\
\hline & Median (min-max) & $63.5(18-92)$ & $52(18-96)$ & \\
\hline \multirow[t]{2}{*}{ Gender, n (\%) } & Female & $116(19.4)$ & $483(80.6)$ & $0.654^{\mathrm{b}}$ \\
\hline & Male & $136(18.4)$ & $603(81.6)$ & \\
\hline \multirow{2}{*}{$\begin{array}{l}\text { Type of consultation, } n \\
(\%)\end{array}$} & Urgent & $187(15.4)$ & $1027(84.6)$ & $0.001^{b}$ \\
\hline & Routine & $65(52.4)$ & $59(47.6)$ & \\
\hline \multirow[t]{10}{*}{ Requested by, n (\%) } & $\begin{array}{l}\text { Emergency department } \\
\text { (green zone) }\end{array}$ & $100(11.6)$ & $764(88.4)$ & $0.001^{\mathrm{c}}$ \\
\hline & $\begin{array}{l}\text { Emergency department } \\
\text { (yellow zone) }\end{array}$ & $76(23.4)$ & $249(76.6)$ & \\
\hline & $\begin{array}{l}\text { Emergency department } \\
\text { (red zone) }\end{array}$ & $4(23.5)$ & $13(76.5)$ & \\
\hline & Internal medicine & $51(53.7)$ & $44(46.3)$ & \\
\hline & Anesthesia & $14(77.8)$ & $4(22.2)$ & \\
\hline & $\begin{array}{l}\text { Obstetrics and } \\
\text { Gynecology }\end{array}$ & $1(11.1)$ & $8(88.9)$ & \\
\hline & Infectious diseases & $3(100.0)$ & $0(0.0)$ & \\
\hline & Orthopedics & $3(60.0)$ & $2(40.0)$ & \\
\hline & Urology & $0(0.0)$ & $1(100.0)$ & \\
\hline & Other & $0(0.0)$ & $1(100.0)$ & \\
\hline \multirow[t]{2}{*}{ Time of request, $n(\%)$} & Within office hours & $78(21.3)$ & $289(78.7)$ & $0.164^{\mathrm{b}}$ \\
\hline & Outside office hours & $174(17.9)$ & $797(82.1)$ & \\
\hline \multirow[t]{2}{*}{ Type of admission, $n(\%)$} & Outpatient & $180(14.9)$ & $1026(85.1)$ & $0.001^{b}$ \\
\hline & Inpatient & $72(54.5)$ & $60(45.5)$ & \\
\hline \multirow[t]{6}{*}{ Diagnosis, n (\%) } & Upper GI disorder & $122(12.8)$ & $829(87.2)$ & $0.001^{b}$ \\
\hline & Hepatobiliary disorder & $18(13.8)$ & $112(86.2)$ & \\
\hline & $\begin{array}{l}\text { Colon, rectum, anus } \\
\text { (proctology) }\end{array}$ & $100(93.5)$ & $7(6.5)$ & \\
\hline & Trauma & $8(16.0)$ & $42(84.0)$ & \\
\hline & $\begin{array}{l}\text { Skin-soft tissue } \\
\text { disorder }\end{array}$ & $0(0.0)$ & $10(100.0)$ & \\
\hline & Other & $4(4.4)$ & $86(95.6)$ & \\
\hline \multirow[t]{5}{*}{ Type of surgery, n (\%) } & Upper GI & $0(0.0)$ & $343(100.0)$ & $0.001^{\mathrm{c}}$ \\
\hline & Hepatobiliary & $0(0.0)$ & $87(100.0)$ & \\
\hline & Hernia surgery & $0(0.0)$ & $42(100.0)$ & \\
\hline & Proctology & $9(60.0)$ & $6(40.0)$ & \\
\hline & Other & $2(13.3)$ & $13(86.7)$ & \\
\hline \multirow[t]{2}{*}{ Mortality, n (\%) } & No & $109(9.5)$ & $1039(90.5)$ & $0.001^{b}$ \\
\hline & Yes & $143(75.3)$ & $47(24.7)$ & \\
\hline \multirow[t]{2}{*}{ Response time (min) } & Mean \pm SD & $116.4 \pm 123.9$ & $113.6 \pm 101.0$ & $0.892^{\mathrm{d}}$ \\
\hline & Median (min-max) & $85.5(20-1440))$ & $89(20-1440)$ & \\
\hline
\end{tabular}

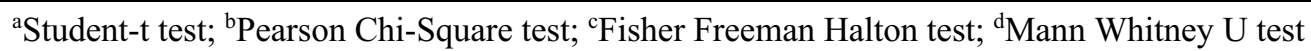


Table 3. Study variables according to type of consultation

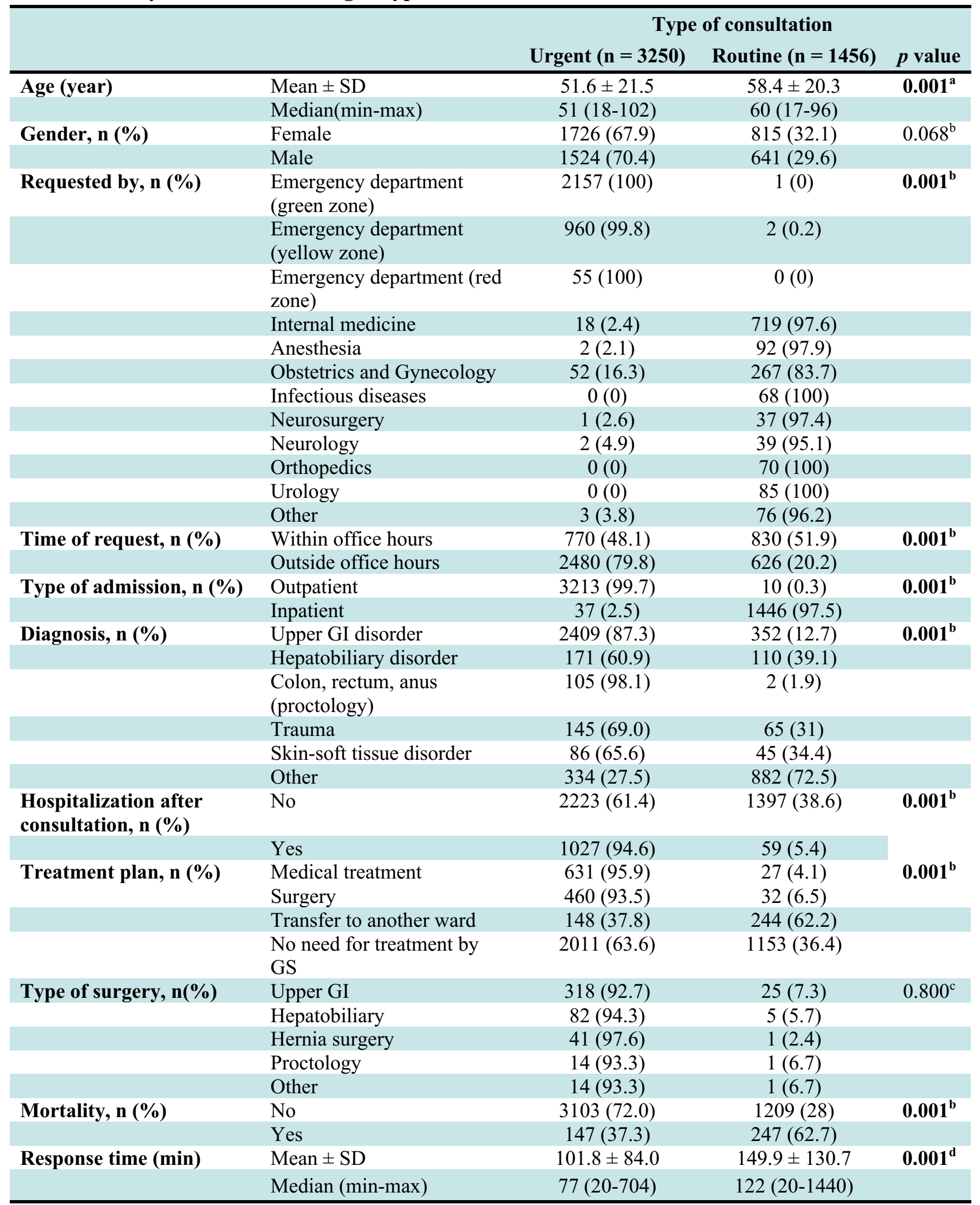

${ }^{\mathrm{a} S t u d e n t-t}$ test; ${ }^{\mathrm{b}}$ Pearson Chi-Square test; ${ }^{\mathrm{c}}$ Fisher Freeman Halton test; ${ }^{\mathrm{d}}$ Mann Whitney U test 
patient gender and type of surgery (see Table 3 ).

\section{DISCUSSION}

The current analysis of overall consultations requested from the department of general surgery during the 2019 calendar year at a tertiary care hospital revealed that most of consultations to be urgent outpatient consultations related to upper GI disorders and to be requested outside the office hours and by emergency department in most of cases. Notably, the surgical pathology was confirmed only in one third of consultations, while two third of consultations requested from the department of general surgery were not associated with a surgical pathology or a need for treatment by general surgeons. Majority of consultations with confirmed surgical pathology were managed on an inpatient basis in the general surgery ward either with medical or surgical treatment.

Our findings seem in accordance with data from a recent study in Turkey regarding the analysis of 221 consultations requested from the department of general surgery over 6-month, which indicated that majority $(91.9 \%)$ of consultations were requested by the emergency services and the rate of patients who were found to have surgical disease was 33\% [3]. This emphasizes the considerably high possibility of a consultation requested from the department of general surgery not to be associated with a confirmed surgical pathology. Nonetheless, while high rates of inappropriate consultations which resulted in no need for management by general surgeon in our cohort seems notable, it should be noted that urgent outside-officehours consultations and consultations requested by emergency department were more likely to be confirmed with surgical pathology after reviewed by general surgeons. Hence, the consultation practice should be improved particularly for the routine within-officehours consultations as requested by clinics other than emergency service.

Accordingly, in the current study, urgent consultations and those related to proctology were both more likely to have a surgical diagnosis after general surgery assessment, while basically treated on an inpatient and an outpatient basis, respectively. This seems in line with well-established efficacy, safety and tolerability of day care proctological procedures a strategy that re- duces costs and release beds for major surgeries without increasing morbidity or mortality $[9,10]$.

Notably, general surgery consultations for lower GI disorders were more likely to be associated with confirmed surgical pathology than those for upper GI and hepatobiliary disorders as well as those for trauma, while the lowest rate of confirmation was evident for consultation related to skin-soft tissue disorders. This seems also notable given that when confirmed to be associated with a surgical pathology after consulted by general surgeon, the main treatment strategy seems to be an outpatient management in case of lower GI disorders, whereas an inpatient management for all other disorders. Moreover, urgent consultations and inpatient management of confirmed surgical pathologies were more common among survivors.

Indeed, upper gastrointestinal bleeding per se comprised nearly two thirds of consultations requested from the department of general surgery in our study. Although this seems in accordance with consideration of acute upper gastrointestinal bleeding is very a common medical emergency [11], surgical pathology was confirmed only in one third of these cases when consulted by a general surgeon. Thus, our findings emphasize likelihood of incompatible or unnecessary consultations to be requested from the department of general surgery particularly in case of suspected upper gastrointestinal bleeding, possibly in relation to avoid a delayed endoscopy referral as early endoscopy within $24 \mathrm{~h}$ of admission has strongly been recommended by the international guidelines $[12,13]$.

In the current study, trauma comprised less than $5 \%$ of consultations requested from the department of general surgery, which seems to be related to location of the study hospital in an exurban area outside major metropolitan with relatively low traffic accident or crime rates.

The higher rate of mortality among consulted patients who subsequently managed via medical treatment rather than surgery seems to be in accordance with higher mortality, re-admission and consultation/referral rates reported in patients admitted to surgical departments who are not operated than those operated, as associated with greater medical complexity and urgency of admission in these patients [14]. Hence the association of urgent consultations with lesser likelihood of mortality seems also consis- 
tent with the fact that they were managed by hospitalization to general surgery ward in most of cases.

Although the lower response time to urgent vs. routine consultations in our study support that the urgency of the patient is the most important factor affecting the duration of consultation [15], median response time of $77 \mathrm{~min}$ seems longer than the recommended 30-minute response period for urgent consultations [16]. Similarly, in a past study on consultations requested by emergency department in Turkey, authors also noted a longer than expected response time (median: $96 \mathrm{~min}$ ) for urgent consultations [16]. Although prolonged response time to urgent consultations requested by an emergency department has been considered to adversely affect the operation of the emergency service [16], response time to consultation from general surgery was not associated with likelihood of consultation to result in confirmed surgical pathology or inpatient management by general surgery in our study.

Possibility of inappropriateness of required consultation was also reported in other departments; for example, in a 2-year retrospective study regarding 338 consultations requested from pulmonary diseases department authors reported that majority of the consultations were from the emergency department, while confirmation of pathology regarding pulmonary diseases was evident only in $42 \%$ of consultations [17].

High-functioning healthcare systems aim to safely optimize surgical yield, with the highest percentage of ambulatory general surgery patients receiving indicated elective surgery without any need for unanticipated emergent or urgent interventions [6]. Thus, consultations requested from the department of general surgery should also comply with the best practice in surgical care delivery in terms of enabling the patients who would most benefit from a surgical intervention to be evaluated by surgical clinicians during limited ambulatory clinic visit times and scheduled for surgery and those who would not benefit from a surgical intervention to remain in primary care [6].

Indeed, in past study of 1743 electronic consultations submitted to general surgery, authors reported the association of using an integrated electronic consultation and referral system (in which all referrals are submitted electronically and reviewed by a general surgery clinician) with a significant increase in the rate of patients scheduled for a subsequent surgical intervention and thus surgical yield of an ambulatory gen- eral surgery service (from 35\% to $46 \%$ ) [6].

Notably, the request of consultation after proper triage and evaluation by the responsible physician based on predefined written algorithms, as well as continuous evaluation and follow-up of the quality of consultation service by each clinic are considered important steps to prevent the incompatible or unnecessary consultation requests $[6,16]$.

It should also be emphasized that on the basis of knowledge and practice on general surgery gained during medical education, emergency department or outpatient physicians are in fact capable of discriminating non-urgent general surgery issues that could be referred directly to outpatient clinic instead of requiring a formal consult by the inpatient service. Hence, unnecessary consultations seem to be prevalent due to malpractice concern or low self-confidence, and improved consultation practice in terms of these concerns seems important given its potential impact on efficiency and patient care.

\section{Limitations}

Certain limitations to this study should be considered. First, due to the retrospective design it is impossible to establish any cause-and-effect relationships. Second, potential lack of generalizability seems another important limitation due to single-center design.

\section{CONCLUSION}

In conclusion, this retrospective analysis of consultations requested from the department of general surgery during the 2019 calendar year at a tertiary care hospital revealed that most of the consultations were urgent, outside the office hours and outpatient consultations requested by the emergency department. The surgical pathology was confirmed only in one third of consultations, while urgent consultations and those related to proctology were both more likely to have a surgical diagnosis after general surgery assessment and basically treated on an inpatient and an outpatient basis, respectively. Moreover, urgent consultations and inpatient management of confirmed surgical pathologies were more common among survivors. Our findings indicate improved consultation practice and in-clinic feedback assessment of quality of requested consultations, particularly for routine requests and re- 
quest by clinics other than emergency service to enable surgical evaluation for the patients who would most benefit from a surgical intervention and thereby to increase the efficiency of consultation practice by preventing the incompatible or unnecessary consultation requests and related healthcare resource utilization.

\section{Authors' Contribution}

Study Conception: ML, OA; Study Design: ML, OA; Supervision: ML, OA; Funding: ML, OA; Materials: $\mathrm{ML}, \mathrm{OA}$; Data Collection and/or Processing: ML, OA; Statistical Analysis and/or Data Interpretation: ML, OA; Literature Review: ML, OA; Manuscript Preparation: ML, OA and Critical Review: ML, OA.

\section{Conflict of interest}

The authors disclosed no conflict of interest during the preparation or publication of this manuscript.

\section{Financing}

The authors disclosed that they did not receive any grant during conduction or writing of this study.

\section{REFERENCES}

1. Lee RS, Woods R, Bullard M, Holroyd BR, Rowe BH. Consultations in the emergency department: a systematic review of the literature. Emerg Med J 2008;25:4-9.

2. Woods RA, Lee R, Ospina MB, Blitz S, Lari H, Bullard MJ, et al. Consultation outcomes in the emergency department: exploring rates and complexity. CJEM 2008;10:25-31.

3. Kahramanca Ş, Kaya O, Azılı C, Güzel H, Özgehan G, İrem $B$. The role of general surgery consultations in patient management. Ulus Cerrahi Derg 2013;29:20-4.

4. Jung KY, Kim S, Kim K, Lee EJ, Kim K, Lee J, et al. Frequent mobile electronic medical records users respond more quickly to emergency department consultation requests: Retrospective Quantitative Study. JMIR Mhealth Uhealth 2020;8:e14487.

5. Tuot DS, Leeds K, Murphy EJ, Sarkar U, Lyles CR, Mekonnen $\mathrm{T}$, et al. Facilitators and barriers to implementing electronic referral and/or consultation systems: a qualitative study of 16 health organizations. BMC Health Serv Res 2015;15:568.

6. Ulloa JG, Russell MD, Chen AH, Tuot DS. A cohort study of a general surgery electronic consultation system: safety implications and impact on surgical yield. BMC Health Serv Res 2017; $17: 433$

7. Irfan M, McGovern M, Robertson I, Waldron R, Khan I, Khan $\mathrm{W}$, et al. Operative surgical yield from general surgical outpatient clinics; time to change the way we practice? Ir Med J 2013;106:209-11.

8. Gupta PJ. Ambulatory proctology surgery-an Indian experience. Eur Rev Med Pharmacol Sci 2006;10:257-62.

9. Sobrado CW. Outpatient surgical proctology--past, present and future. Arq Gastroenterol 2005;42:133-5.

10. Siau K, Hodson J, Ingram R, Baxter A, Widlak MM, Sharratt $\mathrm{C}$, et al. Time to endoscopy for acute upper gastrointestinal bleeding: Results from a prospective multicentre trainee-led audit. United European Gastroenterol J. 2019;7:199-209.

11. NICE. Acute upper gastrointestinal bleeding in over 16s: management, 2012. Available from: https://www.nice.org.uk/guidance/cg141. Accessed 20 February 2019.

12. Gralnek IM, Dumonceau JM, Kuipers EJ, Lanas A, Sanders DS, Kurien M, et al. Diagnosis and management of nonvariceal upper gastrointestinal hemorrhage: European Society of Gastrointestinal Endoscopy (ESGE) Guideline. Endoscopy 2015;47:1-46.

13. Montero Ruiz E, Barbero Allende JM, Melgar Molero V, Rebollar Merino Á, García Sánchez M, López Álvarez J. Do surgeons have more difficulties in the hospital care of non-surgery patients than with surgery patients? Cir Esp 2015;93:334-8.

14. Hexter DA, Henry GL. Working with consultants. Foresight 2002;53:1-7.

15. Yilmaz E, Yilmaz MA, Cander B. Evaluation of the request for consultations in the emergency department of Okmeydani Training and Research Hospital between 2014 and 2015. Eur Arch Med Res 2018;34:182-7.

16. Çobanoğlu U. [Evaluation of the cases consulted by chest surgery department in a university hospital]. Tur Toraks Der. 2009;11:117-21. [Article in Turkish] 